\title{
DE LA TOLERANCIA, SU CONTEXTO Y UNA POSIBLE RELACIÓN CON EL "NOMBRE GENERAL” DE PROPIEDAD EN JOHN LOCKE*
}

\author{
LEONIDAS MONTES L. \\ Universidad Adolfo lBáÑEZ, CHILE
}

\begin{abstract}
Resumen
El propósito de este ensayo es doble. Primero, recordando la atmósfera histórica en la cual Locke vivió, el objetivo es mostrar que su pensamiento estuvo muy influenciado por el contexto general de Inglaterra durante la segunda mitad del siglo XVII. Segundo, después de analizar el contexto que marcó su Ensayo sobre la Tolerancia y su Carta sobre la Tolerancia, y las diferencias principales entre ambas obras, seguirá un breve análisis del complejo concepto de propiedad lockeana. Se argumentará que una lectura diferente de propiedad que considera el amplio sentido del concepto clásico de propriety, que sería consistente con la definición de lo que Locke denomina bajo el "nombre general" de propiedad ("vida, libertades y posesiones"), podría incluir libertad individual en materias religiosas. Si esta interpretación es factible, es decir, si el concepto de propiedad de Locke pudiera comprender libertad de conciencia en asuntos religiosos, entonces la sociedad civil debería necesariamente incluir tolerancia.
\end{abstract}

Abstract

The purpose of this paper is twofold. First, by recovering the historical atmosphere in which Locke lived, the aim is to show that his thought was very much influenced by the general context of England during the second half of the seventeenth century. Second, after analizing the context that shaped his Essay on Tolerance and his Letter on Tolerance, and the main differences between both works, a brief analysis of Locke's complex concept of property in his second Treatise will follow. It will be argued that a different reading of property that takes into account the broader classical meaning of "propriety", which would be consistent with Locke's definition of what he terms by the 'general name' of property ('Lives, Liberties and Estates'), could entail individual liberty in religious matters. If this interpretation is feasible, i.e., if Locke's concept of propriety could comprise freedom of consciousness in religious matters, then Locke's civil society should necessarily entail tolerance.

\section{PALABRAS CLAVE • Historical • Context • Property • Liberty • Tolerance}

\section{INTRODUCCIÓN}

Como es usual con los grandes maestros, diversas lecturas emanan de sus obras. Generalmente los argumentos esbozados para defender una postura particular son distintas versiones acerca de "lo que quiso decirnos". A menudo estas reconstrucciones racionales suelen traicionar la comple-

* Una versión preliminar de este ensayo fue presentada en las "Primeras Jornadas Internacionales de Ciencias del Derecho Profesor Aníbal Bascuñán", en la Facultad de Derecho de la Universidad de Chile, el 11 de noviembre de 2004. Agradezco las preguntas y acotaciones de la audiencia, en particular a Miguel Arellano, Norma Goethe, y Carlos Ruiz. Por último, estoy en deuda con Oscar Godoy y Héctor Martinovic por sus perceptivos y expeditos comentarios. 
ja realidad historiográfica. Hoy hablamos de John Locke, sin duda con justas razones, como el padre del liberalismo, un notable antepasado intelectual de nuestra sociedad capitalista. Sin embargo, este juicio, sumado a las dificultades que encierran los epítetos "liberal" o "sociedad capitalista", sigue siendo motivo de discusión.

Tradicionalmente han existido tres corrientes interpretativas contemporáneas que han dominado la industria intelectual del legado de Locke. Macpherson (1964, [1962]) visualiza a Locke como el burgués que desarrolla los cimientos del "individualismo posesivo" que caracteriza al homo economicus del capitalismo moderno. La Escuela de Chicago, destacando la importancia del concepto de propiedad, argumenta que Locke defiende una posición conservadora liberal (ver, por ejemplo, Cox, 1960; Tarcov, 1984; Grant, 1987). Ambas posturas mantienen cierta relevancia en el debate actual, pero recientemente la posición adoptada por Dunn (1969), enfatizando lo fundamental del carácter religioso de su empresa, y cómo este compromiso tiene implicancias en su pensamiento político en general, ha producido un giro importante en los últimos años (ver, por ejemplo, Marshall, 1994). Sin duda existen sólidos argumentos que sustentan estas distintas posiciones, y no parece osado argüir que todas estas interpretaciones de alguna manera se aproximan a la realidad. Pero para comprender el sentido de "lo que quiso decirnos", y más importante aún, la intención que tenía Locke al escribrir su obra, es necesario situarnos en el contexto durante el cual le tocó vivir.

Dado este último punto de carácter metodológico, este ensayo comenzará con una descripción introductoria del contexto histórico que le tocó enfrentar a John Locke, de manera tal que podamos leer los textos de Locke conscientes de éste. Por ello, el primer objetivo de este ensayo es recalcar la importancia que juega el contexto histórico en el pensamiento de Locke. Inmediatamente después, en la sección 3 y 4, se discutirán el Ensayo sobre la Tolerancia y la Carta sobre la Tolerancia, respectivamente, para poder comprender las diferencias entre ambos textos y la evolución del pensamiento de Locke en la cuestión de la tolerancia religiosa. De esta manera su pensamiento maduro en su Carta sobre la Tolerancia podrá ser interpretado a la luz de su segundo tratado (su Ensayo sobre el Gobierno Civil). Después de comprender la importancia del contexto para interpretar las obras de Locke, el segundo objetivo de este ensayo será, entonces, presentar una tesis respecto a una posible relación entre la teoría de la propiedad de Locke y la tolerancia. Para ello, finalmente, en la sección 5 , después de un breve análisis de la teoría de la propiedad en Locke como fundamento de la sociedad civil, se pretende sugerir no sólo que la libertad religiosa formaría parte de un concepto de propiedad más amplio en Locke, sino también que la tolerancia debe ser garantizada por este orden social.

\section{LA VIDA DE JOHN LOCKE Y SU CONTEXTO ${ }^{1}$}

\section{De la academia a la política}

John Locke nació en un pueblo al suroeste de Inglaterra en 1632. Su padre era un abogado calvinista. Pese a que era un profesional independiente, con buena situación económica, su bien- 
estar básicamente dependía de una familia parlamentaria. Esta conección le permitió a su hijo no sólo asistir al prestigioso Colegio de Westminster, sino también ser aceptado a los veinte años como estudiante en el Christ Church College, en la Universidad de Oxford. Su carrera académica, graduándose como BA y posteriormente como MA, hasta ser nombrado "Censor" de filosofía moral en 1664, seguía el curso tradicional. Durante sus quince años en Oxford escribió un par de ensayos acerca de tolerancia religiosa y algunas cátedras en el tema de las leyes naturales. Hasta ese entonces su vida parecía bastante plana, salvo por el inusual hecho de que habría desistido de seguir una carrera clerical, como era acostumbrado en las universidades de aquella época, optando por el estudio de la medicina. Gracias a esto último, un hecho fortuito cambiaría completamente el curso de su existencia.

En 1666, el terrible año del incendio de Londres y la plaga, Locke conoce casualmente a Lord Ashley, figura política clave en la corte de Carlos II, que posteriormente sería conocido como el primer Earl de Shaftesbury. El noble inglés padecía de una afección al hígado que era mortal. En una de sus visitas a las aguas termales de Astrop, en Oxford, para aliviar su dolor, las botellas de agua le fueron llevadas no por su doctor habitual, sino por un amigo de éste, que era precisamente John Locke. Así comenzó esta famosa y afortunada amistad. En menos de un año Locke ya habitaba con la familia como asesor y médico del poderoso Lord Ashley.

Sin embargo, fue el milagro médico el que pavimentó el futuro de John Locke. Personalmente dirigió una osada operación para remover el abceso que afectaba al hígado de Lord Ashley, insertando además un pequeño tubo de oro por la pared del estómago, con el objeto de evitar futuras malformaciones. Esta hazaña médica no sólo lo hizo famoso dentro de la profesión, sino que además le granjeó el eterno agradecimiento de quien sería su mecenas, quien nunca olvidó que le debía la vida a John Locke. Por su parte Lord Ashley fue satirizado a causa de este tubo en el estómago. En efecto, caricaturas de la época lo ilustraban conectado por medio de este tubo a un barril de cerveza. En 1668 Locke, a causa de esta hazaña científica y de su vínculo con Lord Ashley, es nombrado Fellow de la Royal Society.

Sin lugar a dudas, a no ser por Lord Ashley, Locke simplemente no hubiera sido el John Locke que hoy conocemos. Su mecenas era un hombre extraordinario; inmensamente rico, inteligente, influyente y, sobre todo, políticamente muy hábil2. Si bien habría apoyado a Carlos I con los royalistas, terminó del lado del Parlamento antes de que el rey fuera ejecutado en 1649. Posteriormente fue ministro de Cromwell, pero con el tiempo se convirtió en uno de sus grandes oponenentes y, más aún, en uno de los principales arquitectos de la Restauración de Carlos II en 1660. Entre 1667 y, 1683, Locke vivió los años de la Restauración al alero de uno de los personajes públicos más eminentes, participando activamente en la vida política, social e intelectual de ese período.

Durante el primer año de su estadía junto a Lord Ashley, en 1667, Locke compone su An Essay on Toleration (en adelante Ensayo). En este escrito Locke realiza una defensa política del derecho a disentir en materias religiosas. Esto representa un giro importante desde una posición bastante conservadora en asuntos religiosos durante su estadía en Oxford, a una acorde con los preceptos liberales que guiaban a su mecenas. En efecto, en una carta de 1659 Locke se opone abiertamente a la tolerancia. Adicionalmente dos manuscritos, escritos en 1660 y 1661, respectivamente, son 
dirigidos contra Edward Bagshawe, quien defendía el derecho a la libertad de conciencia. En estos manuscritos, escritos en Oxford, Locke argumenta que el deber cristiano es corregir desviaciones e imponer la uniformidad religiosa, si es necesario mediante el uso de las armas. Locke concluye que la tolerancia es impracticable, y que en definitiva sólo conduciría a la guerra civil. Pero finalmente con el Ensayo de 1667, el controvertido mutatis mutandi lockeano ya había tomado curso.

El Ensayo marca un cambio importante en el pensamiento de Locke y que debe ser sopesado en su contexto. Eran tiempos difíciles para aquellos que no comulgaban con las creencias anglicanas. Además, las luchas de poder eran no sólo habituales, sino también inescrupulosas. En 1670 Carlos II, movido por necesidad financiera, firma un tratado sercreto con el rey católico de Francia, Luis XIV, incrementando el temor antipapista. En 1672, Lord Ashley, por ese entonces ya Earl de Shaftesbury, es nombrado Lord Chancellor, el cargo de más poder en Inglaterra, pero es destituido en 1673 al oponerse abiertamente a la política pro católica del rey. En 1675 Locke, aquejado por una tuberculosis al pulmón, viaja junto al Earl of Shaftesbury a Francia. En 1679 regresan a Inglaterra debido a que los Whig obtienen una gran mayoría en las elecciones porlamentarias. La oposición a Carlos II se agudizaba en lo que hoy se conoce como la "Crisis de la Exclusión". La idea que movía al partido de los Whig, uno de cuyos más insignes representantes era Shaftesbury, era defender los derechos del Parlamento elegido, debilitando al mismo tiempo el poder real. Una de las razones más importantes que subyacía a esta crisis política, que se extendió entre 1678 y 1683 , era sin duda religiosa.

En efecto, dado que en 1681 Carlos II había disuelto el parlamento de Oxford, los Whig querían evitar a toda costa la sucesión al trono del hermano católico de Carlos II, el duque de York, futuro Jacobo II. La apuesta era asegurar la sucesión del hijo ilegítimo de Carlos II, el Duque de Monmouth, que era protestante y popular también entre los dissenters, o sea, todos aquellos que no seguían los preceptos de la iglesia anglicana. El supuesto y publicitado Popish plot que habría existido detrás del sucesor católico, fomentado por Shaftesbury, instigó no sólo el fervor popular, sino también el Rye House plot para secuestrar y quizá matar a Carlos II y su hermano el duque de York.

Pese al fracaso del complot y de todas las iniciativas para impedir el ascenso al poder de Jacobo II, la ley del habeas corpus, donde el acusado al ser detenido debía ser presentado al tribunal, es aceptada, constituyéndose en un importante legado para el mundo moderno. Eran tiempos no sólo difíciles, sino bastante peligrosos. Shaftesbury debe escapar a Holanda, donde poco tiempo después muere, acusado de traición. Locke era sospechoso del mismo cargo.

\section{Del exilio a la fama}

No sólo la muerte de Shaftesbury habría afectado a Locke, sino que un hecho específico lo marcaría profundamente durante esta crisis política. El fracaso de la conspiración de Rye House, en la que Locke también habría participado, para secuestrar a Carlos II y su hermano, en septiembre de 1683, no sólo ayudó a la sucesión de Jacobo II, sino que permitió una campaña para aplicar una ley de traición que terminó con la vida de Algernon Sydney y Lord William Rusell, cercano colaborador de Shaftesbury. Locke nunca olvidaría que la acusación de traición contra Sydney no descansaba en evidencia directa por su participación en la Rye House plot, sino en un manuscrito que planteaba que el pueblo era la fuente de la autoridad. Es más, en dicho documento, que hoy 
conocemos como sus Discourses Concerning Government, publicado póstumamente, Sydney defiende el derecho del pueblo para ejercer la justicia sobre un monarca. Este escrito "sedicioso y revolucionario", que le costó la vida a Sydney, contradecía el espíritu ultrarroyalista del Patriarcha de Sir Robert Filmer.

Esta obra de Filmer se había transformado no sólo en la defensa del poder del soberano, tesis que compartía con el Leviathan de Hobbes (1651), sino también en el texto oficial de las políticas Tories de la época. En ese entonces Locke, de acuerdo con las recientes investigaciones de Ashcraft (1987), ya habría escrito sus Two Treatises on Government (el primer tratado entre 1680-1 y el segundo entre 1681-2), donde el foco de ataque, al igual que en el caso de Sydney, es también Filmer. Ante la eventualidad de ser sorprendido encubriendo este manuscrito, que ciertamente habría sido considerado como un acto de sedición, en septiembre de 1683 Locke escapa a Holanda. Poco tiempo después de huir al exilio fue removido, por orden real, de su posición en Oxford. Durante su estadía en Holanda debe encubrir su identidad y también participa en la famosa rebelión de Monmouth en 1685. Pero las fuerzas de Monmouth fueron derrotadas. Este fracaso fue seguido por brutales asesinatos y masivas ejecuciones en la horca. El temor ante este tipo de situaciones acompañó a Locke durante el resto de su vida, y se refleja en el celo que siempre mantuvo al publicar anónimamente sus obras más polémicas.

Durante el exilio Locke ya tenía más de cincuenta años, y pese a que poseía una serie de manuscritos en los que había trabajado como asesor de Shaftesbury, aún no los hacía públicos.

En Holanda conoció a van Limborch, un famoso teólogo holandés, con quien trabó una amistad que inspiraría la composición de la famosa Epistola de Tolerantia. Existen buenas razones para suponer que esta Carta sobre la Tolerancia fue escrita en Holanda a fines de 1685. Su composición habría estado motivada por las circunstancias. Primero que nada, está escrita con una convicción moral que ciertamente refleja la pérdida irreparable de sus amigos y conocidos a partir de 1681. En seguida, en Francia el Edicto de Nantes, que desde 1598 garantizaba la tolerancia religiosa de los protestantes, había sido revocado por el absolutismo católico de Luis XIV. Al mismo tiempo en Inglaterra Jacobo II, que había asumido el trono ese mismo año, trataba de imponer el catolicismo, simplemente ignorando las demandas del parlamento.

Esta era la turbulenta atmósfera que rodeaba a Locke. Era el regreso a las guerras religiosas, a las ya conocidas y terribles consecuencias del dogmatismo llevado al fanatismo extremo. El problema de la tolerancia entre las diferentes iglesias, y de la relación entre el Estado y la Iglesia en asuntos de libertad religiosa, eran el objeto del diálogo entre Locke y su amigo van Limborch. Este último era arminio, seguidor de las doctrinas de Jacobus Arminius, teólogo protestante que, a diferencia de los calvinistas, negaba la predestinación. Ambos compartían los argumentos básicos de la tolerancia religiosa como base para establecer un marco legislativo necesario que permitiera una convivencia pacífica entre cristianos de distintas iglesias.

En 1688 otra revolución sacudía a Inglaterra. Afortunadamente para Locke, el desenlace de esta crisis permitió, al año siguiente, el regreso al trono del rey Guillermo de Orange, protestante, casado con María Estuardo. La llamada "revolución gloriosa" constituiría un cambio radical en la vida de Locke. Ese mismo año, en 1689, John Locke debuta en el mundo de las letras al publicar su famoso An Essay concerning Human Understanding, que se convirtió en un éxito intelectual inmediato, si- 
tuándolo como uno de los grandes filósofos de su época. Ese mismo año se publica en Holanda anónimamente la Epistola de Tolerantia, en latín. Poco después le sigue una traducción al inglés, $A$ Letter Concerning Toleration, publicada en Inglaterra. También, como consecuencia de la paranoia causada por la agitada vida política que le tocó vivir, publica anónimamente sus Two Treatises on Government ${ }^{3}$, obra que ha tenido una influencia enorme en el campo de la filosofía política. El celo con que mantuvo sus escritos en forma anónima es tal que en su correspondencia existen antecedentes de la intensidad con que habría velado por mantener el anonimato hasta su muerte.

Sus últimos quince años de vida, entre su regreso a Inglaterra y su muerte en 1704, fueron muy activos, asumiendo un rol de liderazgo en el quehacer político e intelectual de su país. Participó activamente en la consolidación constitucional y política del nuevo reinado, en la reorganización de la moneda inglesa y en la formación del nuevo Banco de Inglaterra. El autor del Essay on Human Understanding era una figura cuya influencia política y pública habría enorgullecido a su mecenas, el Earl de Shaftesbury. El desconocido académico de Oxford, convertido en el leal asesor de Shaftesbury, se había transformado en una importante e influyente figura intelectual inglesa. Su reputación como filósofo era indiscutible, y todo lo que escribía era importante para el público, simplemente porque él, el Locke del Essay on Human Understanding, lo había escrito.

Después de la "revolución gloriosa", John Locke era el filósofo Whig por excelencia, la nueva figura de la Era de la Razón que no sólo sobresalía en la vita contemplativa, sino también en la vita activa. En este punto existe una curiosa similitud entre Locke y su gran amigo Newton. Ambos eran profundamente admirados por el mundo intelectual, ambos eran extremadamente cautelosos acerca de sus verdaderas creencias religiosas, ambos eran férreos anticatólicos, ambos dedicaban parte importante de sus esfuerzos a especulaciones teológicas, ambos provenían de una tradición puritana que exaltaba el deber, en fin, ambos, de una u otra forma, representaban la nueva imagen del hombre que forjaría el advenimiento de la llustración.

El rango de sus especulaciones intelectuales cuenta, después del exitoso debut de su Essay on Human Understanding, con un poderoso canal para alcanzar al público: la imprenta. En 1694 publica sus Some Thoughts Concerning Education. Sus escritos referentes a la nueva moneda en Inglaterra aparecen en 1691 y 1695. Sus famosas polémicas con Stillingfleet con relación a su Essay on Human Understanding se publican en 1697 y 1699. Dos cartas que suceden la famosa Epistola de Tolerantia circulan en 1690 y 1692. Su Reasonableness of Christianity as delivered in the Scriptures es publicado en 1695, y su Vindication aparece en 1697. Locke dejó también una serie de manuscritos, y una cantidad impresionante de cartas que han sido publicadas en ocho volúmenes. Sin embargo, si bien conocemos todos sus escritos y los detalles de su vida, su figura continúa siendo el objeto de un incesante debate intelectual.

La historia de las ediciones de Two Treatises of Government es compleja, y se complica más aún con las intervenciones de su autor que, aún velando por su anonimato, corrige incesantemente el trabajo de los editores. La primera edición apareció en 1690, en seguida una nueva versión 'diez veces peor que la primera' (que es vendida barata 'para que llegue al lector común') aparece en 1694. La tercera edición de 1698 tampoco satisfizo el perfeccionismo de Locke, por lo que dejó una nueva versión corregida para ser publicada después de su muerte. Esta aparece en 1704 y después de un período de muchas publicaciones se llega a la famosa copia de Christ's College, que es lo más cercano a lo que Locke quiso dejar a la posteridad. Esta es conocida como la sexta edición de 1764, y es el texto estándar que utilizamos hoy. Para más detalles acerca de esto, ver la introducción y la nota editorial de Laslett a Two Treatises of Government (Locke 2000, [1698], pp. 7-11, 127-32). 
En cuanto al Ensayo sobre la Tolerancia y la Carta sobre la Tolerancia (en adelante Carta), ambos escritos difieren en su contexto. El primero, como ya mencionamos, fue escrito en 1667 bajo el alero de Lord Ashley, Earl de Shaftesbury, y probablemente a petición del mismo. En cambio, la Carta fue escrita aparentemente en 1685, durante su exilio en Holanda, motivado por los sucesos ya mencionados en Francia e Inglaterra, e inspirado por las conversaciones entre Locke y el teólogo holandés van Limborch. Esta última obra es el fruto de cierta maduración en la cuestión de la libertad religiosa sobre la base de los fundamentos de su pensamiento político ya desarollado; el Ensayo es más bien una visión política del problema. Es importante aclarar, eso sí, que pese a que no existe una relación directa entre ambos textos, hay, como veremos, una evidente continuidad temática sobre el mismo argumento central entre el Ensayo y la Carta: el polémico problema de la tolerancia en una atmósfera hostil.

\section{EL ENSAYO SOBRE LA TOLERANCIA}

El Ensayo comienza destacando, que en lo referente a la libertad de conciencia, existen dos posiciones irreconciliables, i.e., absoluta obediencia a la verdadera religión o libertad absoluta en materias de conciencia. El gobernante, en el cual se ha depositado la confianza, el poder y la autoridad, tiene el deber de mantener la paz en la sociedad. El supuesto básico del Ensayo es que sin sociedad política los hombres no podrían vivir juntos en forma pacífica, por ello la necesidad del cuerpo político. Este argumento, siguiendo al línea hobbesiana, es contrario a la idea del bon sauvage posteriomente desarrollada por Rousseau. Así, tanto para Hobbes como para Locke, el fin de la sociedad política debe ser el mantenimiento de la paz y la seguridad. Este supuesto, aunque similar al contrato social hobbesiano, difiere en varios puntos. El fin de ambos es el mismo, la paz y la seguridad de la comunidad, pero la forma de lograrlo es diferente. El Leviathan de Hobbes posee poder absoluto, incluso en materias eclesiásticas. El magistrado de Locke carece de tan amplias facultades. Su deber simplemente es asegurar la paz civil y la propiedad de los ciudadanos. En fin, no parece aventurado sugerir que si ambos abogan por la paz, el llamado de Hobbes es más desesperado.

No debemos olvidar tampoco que la publicación del Leviathan en 1651 produjo un revuelo de proporciones en el mundo eclesiástico. La sugerencia de que no sólo el poder político, sino también el poder eclesiástico caía en manos de la autoridad civil, le granjeó a Hobbes la enemistad del mundo religioso. Por tanto el epíteto de "Hobbist", durante la segunda mitad del siglo XVII y gran parte del siglo XVIII, tuvo un carácter más que peyorativo ${ }^{4}$. Implícitamente encerraba lo que en ese entonces era considerado más que un insulto, i.e., la idea de "ateísmo". En efecto, cuando Newton, víctima de su depresión, escribe en medio de su delirio aquella famosa carta de 1693 a su amigo Locke, lo acusa ni más ni menos que de "Hobbist".

Para Locke el rol del gobierno civil es claro: la preservación de la vida. Cualquier acción coercitiva sólo debe justificarse ante la eventualidad de este dictum. Esta nueva doctrina sugiere que el gobernnante no debe entrometerse en asuntos eclesiásticos, limitando el campo de su jurisdic-

$4 \quad$ El epíteto de Hobbist se asociaba también al epicureísmo, por lo que estaba incluido entre lo que se conocía como los "selfish systems" en filosofía moral. En este sentido, sólo Bernard Mandeville alcanzaría una reputación como la de Hobbes, siendo popularmente apodado Man-Devil. 
ción. Al gobierno civil le competen las relaciones entre personas dentro de la sociedad civil; los asuntos religiosos poseen otro carácter. El cómo venerar a Dios, la forma de los ritos, la importancia de éstos, son todos asuntos ajenos al gobierno. El ámbito del gobierno se limita a lo secular, entendido como lo que se distingue de lo eterno, lo que no necesariamente implica un divorcio de la teología. La solución del problema es simple: el gobierno debe velar por la conducta en esta vida, pero no por la preparación a la próxima, que es un asunto completamente personal. La autoridad debe proteger la sociedad, pero en este mundo. En definitiva, la solución radica en el reconocimiento del Estado como un ente secular cuyo propósito no es velar por las creencias religiosas, sino que velar por la vida presente. Hoy en día esta distinción parece trivial, pero en ese entonces esta propuesta era considerada por muchos no sólo contraria a los preceptos de la verdadera religión, sino bastante revolucionaria.

El ambiente en el cual Locke escribió el Ensayo estaba marcado por el Conventicle Act de 1664, que había sido seguido por la Act of Uniformity y la Corporation Act. No sólo se prohibía a aquellos que no comulgaran con los principios anglicanos, los llamados dissenters, ejercer autoridad pública alguna, sino que también prescribía penas civiles contra éstos. Esta serie de medidas se fueron haciendo cada vez más estrictas. Su aplicación y justificación obedecían en parte a la creencia de que el incendio de Londres, la plaga y la derrota naval antes los holandeses, eran el simple y tangible reflejo de la ira de Dios contra el pueblo inglés.

La intención del Ensayo debe ser comprendida como una reacción ante la creciente legislación a favor de imponer la uniformidad de culto utilizando diversos tipos de sanciones civiles. Locke sostenía que esta seguidilla de medidas producirian un desasosiego social, amenazando el objetivo último del gobierno: "to secure the safety and peace" ("asegurar la seguridad y la paz"). Sin embargo, es importante notar que el Ensayo, pese a oponerse a la imposición de la religión anglicana, está escrito desde la perspectiva de quien básicamente comulga con los preceptos de la Iglesia Inglesa. Por ello Locke se refiere a "nosotros" y también a "nuestra iglesia". Además, explícitamente hace ver su desconfianza hacia los católicos romanos, a quienes se refiere peyorativamente como 'Poppists'.

El énfasis del Ensayo está claramente en asuntos del Estado, no eclesiásticos, por ello la pregunta entre "tolerancia o imposición" desempeña el rol principal a lo largo de este escrito, sugiriendo una preocupación más por el Estado que por la iglesia. En conclusión, el Ensayo es un documento político. Sin embargo, si el Ensayo había establecido la dirección en la cual el pensamiento de Locke se dirigía, aún dejaba muchas preguntas sin respuesta, entre ellas la verdadera naturaleza de la autoridad civil y de la iglesia. Si la orientación es clara, Locke todavía no posee el conocimiento del lugar al que aspira llegar. Esto es el parte de la evolución de su pensamiento, cuyos frutos claramente se reflejan en la Carta a través de la maduración de su pensamiento político en sus Dos Tratados sobre el Gobierno.

\section{LA CARTA SOBRE LA TOLERANCIA}

La Carta fue publicada primero en latín en mayo de 1689 en Gauda, Holanda, y posteriormente una traducción al inglés ( $A$ Letter Concerning Toleration), realizada por William Popple, fue publicada en octubre del mismo año. No obstante que ambas publicaciones hayan aparecido en forma 
anónima, existen razones para creer que Locke participó de alguna forma en la traducción al inglés. También resulta curioso mencionar que, pese a que su amigo van Limborch, a quien la Carta estaba sin duda dirigida, ciertamente estaba al tanto de la autoría de Locke, la correspondencia entre ambos detalla la aparición de la Carta como si fuera un hecho ajeno. Es más, tal es el celo que Locke ejerció intentando desligar su nombre de la Carta, que una vez que van Limbarch deslizó en una conversación con un amigo el nombre del verdadero autor de esta obra, esto gatilló una severa recriminación escrita por parte de Locke.

Al mismo tiempo que se publicaba la Carta en latín, en Inglaterra se imponía la Toleration Act. Aunque Locke reconoció en una carta a su amigo van Limbarch que este era un primer paso, estaba aún lejos de alcanzar la tolerancia por ambos deseada. En efecto, la Act of Toleration de 1689 negaba la libertad de culto para los católicos y para aquellos que no creían en la Trinidad. Al igual que Newton, Locke creía en la verdad de las escrituras, y sus especulaciones teológicas lo hacian más cercano al unitarismo, que abogaba por un solo Dios, pero sin negar la existencia histórica de Jesús. Estas creencias negaban implícitamente el rol de la Trinidad, por consiguiente ambos, Locke y Newton, permanecían aún dentro del grupo de los no tolerados, manteniendo sus verdaderas creencias como un asunto muy privado. Recordemos también que aquellos que no participaban de las creencias anglicanas no tenían acceso a cargos públicos. En resumen, los dissenters eran ciudadanos de segunda clase.

El impacto de la Carta fue inmediato. Era una posición política muy radical durante la época. Incluso dentro de los Whig, sólo un pequeño grupo de radicales respaldaba tan osada propuesta. Los poderes que mantenía la hegemonía anglicana reaccionaron airadamente ante lo que consideraban un nuevo complot jesuita para traer el caos y la ruina al país. Incluso se argumentaba que esta Carta era una estrategia de los católicos para facilitar al papa la dominación de Inglaterra. El establishment reaccionó defendiendo la prerogativa de que el gobierno tenía el derecho a usar la fuerza, si era necesario, para que los dissenters reflexionaran acerca de los méritos del anglicanismo como la verdadera religión. Este debate fue inciado por Jonas Proast, y en 1690 Locke responde con A Second Letter Concerning Toleration. Proast contesta, y Locke publica en 1692 A Third Letter Concerning Toleration. En 1703 Proast contesta nuevamente, y Locke no alcanza a finalizar su Fourth Letter Concerning Toleration, que es publicada póstumamente, una vez que en su testamento reconoce la autoría de sus obras publicadas bajo el celo del anonimato.

La Carta es el fruto de más de treinta años de maduración acerca de un problema que preocupó a Locke a lo largo de su vida. Está escrita con la clara intención de apoyar la resistencia de los dissenters ante la imposición por parte del gobierno del anglicanismo como la única religion permitida. En ese entonces los dissenters comprendían sólo cerca del 10\% de la población, pero esa minoría sufrió enormemente durante este período. Multas, confiscación de bienes, encarcelamiento e incluso la muerte, eran el precio que debían pagar los también llamados non-conformists. Después de la Restauración en 1660, Carlos II intentó aprobar medidas tendientes a la tolerancia, produciéndose una pugna de poderes que sólo reveló la clara hegemonía del poder de la Iglesia Anglicana en Inglaterra. 
Popple inicia su traducción de la Carta con una nota al lector. En ésta aparece una frase famosa que ha sido a menudo erróneamente atribuida a Locke, pero que sin duda refleja el ánimo de su escrito: "Absolute liberty, just and true liberty, equal and impartial liberty, is the thing that we stand in need for (Libertad absoluta, libertad justa y verdadera, libertad equitativa e imparcial, es lo que necesitamos)". A diferencia del Ensayo, al comienzo apela a la conciencia de aquellos que han perseguido, tormentado, destruido o matado a otros hombres por motivos religiosos. Este tipo de situaciones son para Locke claramente contrarias a la gloria de Dios, a la pureza de la Iglesia, y a la salvación de las almas. Sus consecuencias son más dañinas que cualquier tipo de disentimiento en materias eclesiásticas. A continuación Locke plantea que la tolerancia es compatible con las Escrituras, y que parece increíble que los hombres aún no vean la necesidad y ventajas de ésta. En efecto, hay que distinguir exactamente entre lo que concierne al gobierno y aquello que concierne a la religión. El gobierno tiene claro su objetivo de procurar, preservar y avanzar en pos de los intereses civiles, pero este objetivo no puede ni debe extenderse a la salvación del alma.

El énfasis en la libertad de la persona implica, necesariamente, que las creencias no pueden ser impuestas por la fuerza. El comportamiento religioso individual, si tiene finalidad alguna, está necesariamente definido sobre la base de una convicción subjetiva. En asuntos privados, cada uno decide cuál es el mejor curso a seguir, y así también debe suceder con cuestiones de conciencia religiosa. El cuidado de alma, como el cuidado de lo que es propio, es algo que pertenece al individuo. Más aún, nadie tiene el derecho de obligar a otro a una acción, que de ser errada, no tendría compensación alguna. En conclusión, todo ser humano tiene el derecho de venerar a su Dios en la forma que le parezca correcta.

Para Locke la iglesia es una asociación voluntaria de hombres. Pero, a su vez, esta asociación tampoco tiene jurisdicción alguna en asuntos terrenales. De esta forma, la autoridad eclesiástica debe ser mantenida dentro de la iglesia, y no extendida a los asuntos civiles, que son de competencia del gobierno. Este es el gran punto de la Carta, y el gran legado político en cuanto a la separación de los poderes del Estado y eclesiástico. Cada institución debe atenerse a los roles que le competen, marcándose así claramente los límites entre lo eclesiástico y lo civil.

A partir de Locke la religión pasa a ser cada vez menos un problema del Estado, y cada vez más un derecho humano individual. Pero cabe destacar que la Carta no incluye a quienes niegan la existencia de Dios, ya que ello, en palabras del propio Locke, "lo disolvería todo". He aquí el carácter religioso de Locke, que no sólo impregna su concepción de la tolerancia, sino que es inmanente a lo largo de la evolución intelectual de este controvertido pensador.

La Carta está escrita en un lenguaje universal. El tono no es el acento político que marca al Ensayo, sino que es la voz de Locke que habla como un filósofo moral que ha vivido y sufrido las consecuencias del fanatismo religioso. 


\section{EL CONCEPTO DE PROPIEDAD}

Una primera lectura de la Carta y del segundo tratado llevaría a pensar que el ámbito de lo religioso es subjetivo, lo que en contraste con la objetividad de la sociedad civil, separaría epistemológicamente y de facto ambos mundos. No obstante, pretendo argumentar, por una parte, que un concepto de propiedad extendido en Locke podría dar cabida a la libertad religiosa ${ }^{5}$, por tanto sería deber de la sociedad civil garantizar el ejercicio de la libertad de culto como algo propio. Por otra parte, la relación entre tolerancia y propiedad es más estrecha: se complementan en lo que constituye el fundamento de la sociedad civil lockeana. En efecto, es la teoría de la propiedad lo que nos permite pasar, en base a Dios y la ley natural (que considera la libertad e igualdad de los hombres), a un arreglo político que garantiza la tolerancia.

\section{El argumento del segundo tratado y el concepto de propiedad}

Después de probar en el primer tratado que Filmer estaba equivocado en cuanto a su interpretación de que Dios había dado superioridad a algunos hombres sobre otros, Locke comienza su segundo tratado definiendo el poder político como un derecho a hacer leyes "for the Regulation and Preservation of Property" ("para la regulación y preservación de la propiedad", Locke, 2001, [1698], II, 3, p. $268)^{6}$. Pero antes de profundizar en este tema de la propiedad, Locke se pregunta por la naturaleza de los hombres. Por la razón sabemos que al ser iguales e independientes "no one ought to harm another in his Life, Health, Liberty, or Possessions" ("nadie debe dañar a otro en su vida, salud, libertad, o posesiones", ibid., II, 6, p. 271). Ahora bien, como todo es obra de un ser omnipotente, en definitiva al ser iguales no sólo somos "his Property" ("su propiedad", ibid.), sino que además no puede existir subordinación entre nosotros. De aquí se sigue que la libertad y la igualdad son cualidades naturales comunes a todos los hombres en cuanto somos obra y propiedad de Dios.

La ley natural es la ley de la razón, y a su vez, como diría Locke, la razón nos lleva a la ley natural. Ahora bien, considerando nuestra igualdad, todos tenemos poder sobre la ley natural en cuanto a que podemos exigir y demandar su cumplimiento en base a la razón. Este derecho natural puede ser ejercido en forma individual, por ejemplo, cuando está en juego la preservación propia. Así "every Man hath a Right to punish the Offender" ("todo hombre tiene el derecho a castigar al ofensor", ibid., II, 8, p 272). Es más, "in the State of Nature, every one has the Executive Power of the Law of Nature" ("en estado de naturaleza, todos tienen el poder ejecutivo de la ley natural", ibid., II, 13, p. 275). La razón nos confirma que esto mismo también debería realizarse con relación a la preservación de la sociedad, ya que las pasiones de los hombres podrían llevar el castigo, mediante la aplicación del derecho de la ley natural, demasiado lejos. Ante este riesgo, el gobierno civil, que proviene del

\footnotetext{
Estoy consciente de las dificultades, limitaciones y consecuencias de esta interpretación, tanto con relación a la postura metodológica que esta reconstrucción racional conlleva, como en cuanto a que la denominación lockeana de propiedad como 'vida, libertad y posesiones' podría no ser más que eso: una simple denominación. Respecto a lo primero, agradezco a Norma Goethe este punto, aclarando que es la tradición clásica inherente al concepto de propiedad y su uso en la época lo que me exime de dejar completamente el contexto en mi tarea interpretativa del concepto de propiedad. En lo segundo, estoy en deuda con Oscar Godoy, quien me llamó la atención sobre este y otros puntos. Respecto a mi propia posición en relación con la historia de las ideas, influenciado por Quentin Skinner y el realismo crítico, propongo una combinación entre el qué está escrito, el por qué y el cómo está escrito. En otras palabras, texto, contexto y significados, respectivamente, desempeñarían un rol en este proceso interpretativo (ver capítulo 1, Montes (2004)).

6 En adelante las traducciones del texto Two Treatises of Government serán de mi autoría.
} 
consentimiento, "is the proper Remedy for the Incoveniences of the State of Nature" ("el remedio apropiado para las inconveniencias de la ley natural", ibid., II, 13, p. 276). Es más, la posibilidad del estado de guerra donde "Force without Right, upon a Man's Person, makes a State of War" ("fuerza sin derecho, sobre la persona del hombre, hacen al estado de guerra", ibid., II, 19, p. 281), es una de las grandes razones para que los hombres abandonen el estado de naturaleza y consientan en una sociedad civil. Pero a diferencia de Hobbes, en Locke la gran razón para dar este paso, de un estado natural a una sociedad, descansa en su concepto de propiedad.

La legitimización de la propiedad a partir de un mundo cristiano donde se parte de la propiedad común, tiene en Locke su fundamento en el trabajo como algo propio. En efecto, si Dios nos dejó la naturaleza en común, en un estado natural sin dominio alguno de nadie sobre algo, donde "every Man has a Property in his own Person" ("cada hombre tiene propiedad sobre su propia persona", ibid., II, 27, p. 287), Locke concluye:

The labour of his Body, and the Work of his Hands, we may say, are properly his. Whatsoever then he removes out of the State that Nature hath provided, and left in it, he hath mixed his Labour with, and joined to it something that is his own, and thereby makes it his Property" ("El trabajo de su cuerpo, y la labor producida por sus manos, podemos decir, son propiamente suyos. Lo que entonces él obtenga del estado que la naturaleza ha provisto y dejado, lo ha mezclado con su trabajo, y esto unido a algo que es de sí mismo, pasa a hacerse su propiedad", ibid., II, 27, pp. 287-8).

Dios nos entregó el mundo en común, para el uso del "industrioso" (ibid., II, 34, p. 291), que mediante su trabajo saca o manumita, por así decirlo, del estado de naturaleza común aquellos objetos donde realiza algún tipo de mano de obra. Poco después Locke extiende su noción del homo faber, planteando la original idea, fundamental en el desarrollo de la economía política desde Adam Smith hasta Karl Marx, de que: "tis Labour indeed that puts the difference of value on every thing" ("es el trabajo ciertamente lo que pone la diferencia de valor en todas las cosas", ibid., II, 40, p. 296). Pero en definitiva la explicación de la legitimidad de la propiedad privada descansa en esta tesis de que todo aquello en común, que es objeto de trabajo, deja este estado de naturaleza para convertirse en propiedad de alguien. Así concluye:

"From all which it is evident, that though the things of Nature are given in common, yet Man (by being Master of himself and Proprietor of his own Person, and the Actions or Labour of it) had still in himself the great foundation of Property; and that which made up the great part of what he applied to the Support or Comfort of his being, when Invention and Arts had improved to the conveniences of Life, was perfectly his own, and did not belong in common to others" "De todo esto es evidente que pese a que las cosas son dadas en común por la naturaleza, no obstante el hombre (siendo dueño de sí mismo y propietario de su propia persona, y de las acciones o del trabajo de ésta) tenía aún en sí mismo el gran fundamento de la propiedad, ese que constituye gran parte de lo que dedica al mantenimiento y bienestar de su ser, cuando las invenciones y la técnica habían mejorado la calidad de vida, era perfectamente propio, y no pertenecía a otros", ibid., II, 44, pp. 298-9).

El problema de la legitimidad de la adquisición de la propiedad material quedaría zanjado según Locke ya que "Labour, in the Beginning, gave a Right of Property" ("el trabajo, en el principio, daría 
un derecho a la propiedad", ibid., II, 45, p. 299). En definitiva es en torno al problema de la propiedad, a las garantías para su uso y goce, que surge la necesidad del gobierno civil ${ }^{7}$.

Después Locke aclara que igualdad es en estricto rigor aquel "equal Right that every Man hath, to his Natural Freedom" ("derecho igual que todo hombre tiene a su libertad natural", ibid., II, 54, p. 304) y la ley "is not so much the Limitation as the direction of a free and intelligent Agent to his proper Interest" " "no es la limitación sino la dirección de cada agente libre e inteligente en pos de su propio interés", ibid., II, 57, p. 305). Esta última frase, sumada a la recurrente idea de que la sociedad civil es "directed to no other end, but the Peace, Safety, and public good of the People" ("dirigido a ningún otro fin que no sea la paz, seguridad y el bien público del pueblo", ibid., Il, 131, p. 353), quizá hubieran emocionado a Bentham tanto como su lectura de Hume.

El cuerpo político surge cuando renunciamos a nuestro poder natural, cuando transferimos éste a la comunidad:

"there only is Political Society, where every one of the members hath quitted this natural Power, resign'd it up into the hands of the Community in all cases that exclude him not from appealing for Protection to the law established by it" ("sólo hay sociedad política cuando cada uno de sus miembros ha renunciado a su poder natural, entregándolo en favor de la comunidad en todos los casos que no lo imposibiliten de apelar a la protección de la ley establecida por ella" ibid., Il, 87, p. 324).

Este es el proceso que da origen al "Legislative and Executive Power of Civil Society" ("el poder legislativo y ejecutivo de la sociedad civil", ibid., II, 88, p. 325). Como seres libres en estado de naturaleza, la incertidumbre de estar constantemente expuestos a la invasión de otros sin seguridad alguna para gozar de lo propio nos lleva a formar la sociedad civil. El precepto "Government has no other end but the preservation of Property" ("el gobierno no tiene otro fin sino la preservación de la propiedad", ibid., II, 94, p. 329) se repite reiteradamente a lo largo del segundo tratado, ya que los hombres, alentados por su propio interés, consienten en dejar el estado de naturaleza para formar la sociedad civil. Esta comunidad o cuerpo político que es una unión voluntaria, evoluciona con el consentimiento de la mayoría, donde cada miembro le entrega su poder al common-wealth ${ }^{8}$.

La razón por la cual los hombres se unen en sociedad es porque en estado de naturaleza estamos permanentemente expuestos a la invasión de otros. Esta incertidumbre no da seguridad alguna, pero al entregar mi poder natural a la sociedad se garantiza la "mutual Preservation of their Lives, Liberties and Estates, which I call by the general Name, Property" "'la preservación mutua de sus vidas, libertades y posesiones, que yo denomino bajo el nombre general de propiedad", ibid., II, 123, p. 350, el subrayado es intencional). Si en el estado de naturaleza podemos ser víctimas de los demás, el fin de la sociedad queda claramente explícito en este pasaje tan citado:

The great and chief end therefore, of Mens uniting into Commonwealths, and putting themselves under Government, is the Preservation of their Property. To which in the state of Nature there are many things wanting ("El gran y principal fin entonces, de los hombres uniéndose en comunidades políticas, poniéndose bajo un gobierno, es la preservación de su propiedad. Respecto a ésta hay, en el estado de naturaleza, muchas carencias", ibid., II, 124, pp. 350-1).

7 Es más, se puede sugerir cierta analogía implícita entre el dinero y la sociedad, ya que ambos surgen por 'mutual consent' ('consentimiento mutuo', ibid., II, 47, pp. 300-1).

8 Pese a que Locke define explícitamente commonwealth como una Civitas, nótese la connotación económica de esta palabra y sobre todo su relación con la idea de la propiedad común inicial en el estado de naturaleza. 
Ciertamente el concepto de "propiedad" anteriormente subrayado es fundamental en Locke, pero ¿sería posible interpretar este concepto de propiedad denominado bajo el "nombre general" que incluye "vida, libertad y posesiones" más allá de sus características materiales e incluir libertad? Si la sociedad civil garantiza la libertad negativa con relación a lo ad extra, ¿podemos entrar al plano de lo ad intra? En otras palabras ¿podemos también comprender propiedad en el sentido subjetivo de las propias creencias, como una interpretación positiva de la libertad: lo propio "para", que no sólo dice relación con la acepción negativa de la libertad?

En la tradición clásica existen fundamentos para ampliar el concepto de propiedad. Por ejemplo, la palabra latina proprius se refiere en un sentido general a lo que no es común comparado con lo otro, o sea lo peculiar ${ }^{9}$. Sin duda lo propio también se extiende al concepto de propiedad en cuanto a posesiones. Curiosamente la palabra proprietas (y recordemos que Locke ocupa indistintamente Propriety o Property) es el latín de idiotes, que deriva de idios (en latín, proprius). Para los griegos la palabra idios, que también implica propiedad privada, dice en general relación con lo privado en oposición a lo público, o si se quiere, con la carencia de lo público. Por ello la palabra idiotes se refiere a aquél sin atribuciones públicas, por ejemplo un habitante que no participa de la vida de la polis (como puede ser el caso de las mujeres, los esclavos, o en general, los bárbaros). Los estoicos en particular habían desarrollado el concepto de oikeiosis que se refiere a lo propio, lo familiar. La oikonomia se refiere al hogar, el lugar donde se habita, y representa lo privado. En ambos casos lo propio trasciende lo material.

En el caso de Hobbes, por ejemplo, éste declara: "and therefore where there is no Own, that is, no Propriety, there is no Injustice; and where there is no coercive Power erected, that is, where there is no common-wealth, there is no Propriety" ("y entonces donde no existe lo propio, esto es, no hay propiedad, no hay injusticia; y donde no hay un poder coercitivo erigido, es decir, donde no hay comunidad política, no hay propiedad", Hobbes 2001 [1651], p. 101). Aquí también se refleja, al margen de las diferencias (y por qué no decirlo, algunas similitudes) con Locke, el amplio sentido de propiedad como lo propio más allá de lo material. Este concepto de propiedad extendida se ha perdido, pese a que durante el siglo XVIII existía claridad respecto a la amplitud del significado de propiedad, lo que nos permite comprender la relevancia moral que adquiere el concepto de propriety en este contexto. Hoy en día el concepto de propiedad se restringe con mayor frecuencia al de propiedad material, pero el amplio sentido de propiedad como lo propio es la motivación para reflexionar respecto a la relación entre tolerancia y propiedad en Locke ${ }^{10}$.

Lo que Locke define bajo el "nombre general" de vida, libertad y posesiones son los grandes valores que componen el sentido de "propiedad". Existe ciertamente un orden, sin vida no hay libertad, y sin la vida y la libertad no se pueden tener posesiones con seguridad. En este proceso,

$9 \quad$ Nótese nuevamente la relación entre la raíz etimológica de peculiar y pecuniario: pecus es el latín para ganado. El sentido económico del ganado no es casualidad si pensamos que la palabra capital está emparentada con cattle (ganado en inglés). En efecto, el propio Adam Smith narra una historia donde un embajador francés visita a los tártaros y les pregunta por la cantidad de oro y plata que poseen. El anfitrión por su parte le pregunta por la cantidad de ganado en Europa. Smith, contra el mercantilismo, concluye irónicamente que el tártaro estaría más cercano a la realidad.

10 Por ejemplo, en economía neoclásica se comprende el concepto de lo propio en términos de preferencias, donde diferentes individuos tendrán distintas preferencias reflejadas en sus funciones de utilidad ordinal (curvas de indiferencia). En los fundamentos de la economía este supuesto equivale a llevar al límite la subjetividad del concepto de lo propio; en el caso de Locke, sólo pretendo ampliarlo al caso de la libertad positiva para ejercer mi derecho a elegir mis creencias, sin que esto dañe lo establecido por consenso en la sociedad civil, que garantizaría mi libertad negativa. 
una vez acordada la sociedad civil, ¿no sería posible revertir este orden? Es decir, una vez alcanzada la seguridad de nuestras posesiones, ¿podríamos leer la propiedad lockeana en toda su amplitud, incluyendo ahora la libertad positiva que implica la conciencia religiosa? Lo que Locke define bajo el "nombre general" de propiedad pareciera extenderse a lo privado, incluyendo la libertad que es de carácter subjetivo. La idea de la autopreservación ya estaba muy clara en Hobbes, pero la idea de la libertad como algo propio requiere cierta reflexión. Como hijos de Dios iguales, los hombres nacen libres, y esta libertad es un atributo propio, privado. Analicemos brevemente algunos pasajes de la Carta para continuar desarrollando esta tesis.

\section{Tolerancia y propiedad en la "Carta"}

No olvidemos que pese a que los dos tratados fueron publicados anónimamente en 1698, el segundo tratado, o el Ensayo acerca del Verdadero Origen, Alcance y Fin del Gobierno Civil (Essay concerning the True Original, Extent, and End of Civil Government), fue escrito entre 1681 y 1682. Este punto es importante, ya que el Ensayo acerca del Gobierno Civil provee el fundamento de la sociedad civil que más tarde se repite en la Carta, escrita en 1685 y publicada en 1689. Es más, como parte de la separación entre el poder eclesiástico y civil, la teoría de la propiedad de Locke sería, a mi juicio, no sólo cronológicamente anterior, sino que el telón de fondo para una lectura de la tolerancia como el ejercicio de la libertad de culto que necesariamente emana de una sociedad civil lockeana.

La tolerancia en asuntos religiosos, escribe Locke, se ajusta tanto al Evangelio como a la razón. Distinguiendo gobierno civil de religión, nos recuerda:

El Estado es, a mi parecer, una sociedad de hombres constituida para preservar y promover simplemente los bienes civiles. Llamamos bienes civiles la vida, la libertad, la salud, la inmunidad del dolor, la posesión de cosas externas, tales como la tierra, el dinero, los enseres, etc. (Locke, 2001, [1689], p. 25).

Lo que Locke denominaba bajo el "nombre general" de propiedad, "vida, libertad y posesiones", ahora aparece definido como bienes civiles. Esta es la garantía a la libertad negativa, pero mi libertad para creer, como algo 'propio', adquiere un carácter civil.

En seguida repite el precepto del segundo tratado e insiste en que "ninguna persona privada debe, en ningún caso, perjudicar o disminuir los bienes civiles de otro" (ibid., p. 34). Cuando se trata de lo propio cada uno tiene pleno derecho a decidir por sí mismo qué le conviene hacer. Dado que en asuntos religiosos "el cuidado, por tanto, del alma de cada hombre le corresponde a él mismo, y se lo debe dejar solo" (ibid., p. 41), está claro que la libertad de culto es parte de la libertad de lo propio. Inmediatamente después de esta cita compara el "cuidado del alma" con el "cuidado del patrimonio", que también corresponde al ámbito de lo propio. A nadie se lo puede obligar a ser rico porque cada uno es dueño de lo propio y lo administra como le plazca. Lo mismo ocurre en asuntos religiosos: a nadie se lo puede obligar a seguir un dogma. Locke repite que en cuestiones religiosas al hombre hay que dejarlo consigo y con su conciencia.

Para Locke es claro que "las leyes no protegen la verdad de las opiniones, sino la seguridad e integridad de los bienes de todos los ciudadanos y de la sociedad en su conjunto" (ibid., p. 60). Dentro de estos bienes está la libertad, y Locke insiste en que "cada uno es juez último y supremo de 
su salvación, porque se trata de algo que le concierne solamente a él" (ibid., pp. 61-2). Por tanto pareciera ser deber de la sociedad civil garantizar la libertad de culto como expresión de lo propio.

Sin la intención de insistir en la búsqueda de un argumento proto-utilitarista en Locke, sólo quiero plantear la analogía de que así como la sociedad civil tiene un fin de conveniencia, la tolerancia también es útil para la vida, o al menos útil para evitar muertes injustas. El "bien público, terrenal y mundano" es la única razón, válida para todos, para formar la sociedad, "y es el único fin del estado" (ibid., p. 63). Pero parte de la libertad que les queda a los ciudadanos, y lo plantea Locke explícitamente, es la libertad para que cada uno haga lo que crea respecto a su vida futura, obedeciendo a Dios y a las leyes.

En conclusión, así como "la sociedad política ha sido instituida sólo para asegurar a cada hombre la propiedad de los bienes de esta vida", la tolerancia, que garantiza la libertad de culto, es parte y fundamento de nuestra sociedad civil, y es, en esta interpretación que he intentado esbozar, también una consecuencia de una lectura más amplia del concepto de propiedad en Locke. De ser así, la libertad positiva para ejercer mi derecho a elegir mi religión como algo propio, debe estar garantizada por la sociedad civil.

\section{BREVES CONCLUSIONES}

Si la lectura más común de la tolerancia emana de un análisis de su concepto de libertad, he intentado sugerir la posibilidad de que la libertad religiosa sea parte de la teoría de la propiedad, por lo cual la tolerancia sería condición necesaria de la sociedad civil lockeana ${ }^{11}$.

El legado de John Locke presenta el pensamiento de un intelectual que ha ejercido una influencia innegable. En particular su defensa de la tolerancia, como respeto al derecho religioso individual, representa una llave fundamental para el desarrollo del mundo moderno. Asimismo, su compleja teoría de la propiedad pone el énfasis en lo propio, que más allá de la mera connotación material se vincula a aspectos tan profundos como la libertad y la tolerancia. Con Locke el lenguaje del deber pierde protagonismo frente al nuevo lenguaje del derecho. Una importante consecuencia de este giro para la historia del pensamiento político moderno ha sido el hecho de que el ciudadano, contando con garantías civiles que resguarden lo propio, puede finalmente dar a conocer la voz de su conciencia.

Aunque no ha sido mi intención, el concepto de propiedad lockeano extendido que he intentado dilucidar podría prestarse para una analogía con el concepto de lo propio en la racionalidad económica, así como para una interpretación à la Macpherson. Respecto a lo primero, al margen de lo sugerido en la nota 10, existe un contexto moral de lo propio en Locke, que sería sustituido por una concepción amoral de lo propio en términos del homo economicus. En cuanto a lo segundo, el énfasis de Macpherson (1964, [1962]) es una lectura marxista basada en el proceso de apropiación material por motivos egoístas, y no en el contenido de propio. Macpherson se refiere explícitamente a la confusión de Locke en su definición de propiedad, que a veces incluye "vida, libertad y posesiones", y otras veces no. Pero él ve en esta confusión un cambio desde un paradigma tradicional hacia uno de los valores burgueses (1964, [1962], p. 220). Este ensayo pregunta por las consencuencias si no existiera tal confusión y el concepto de propiedad para Locke simplemente comprendiera libertad. 


\section{REFERENCIAS}

Ashcraft, Richard. 1987. Locke's Two Treatises of Government. London: Unwin Hyman.

Bourne, Henry Richard Fox. 1876. The Life of John Locke. London: H. S. King.

Cox, Richard Howard. 1960. Locke on War and Peace. Oxford: Clarendon Press.

Cranston, Maurice. 1957. John Locke, a Biography. London: Longmans.

Dickinson, Harry Thomas. 1977. Liberty and Property: Political Ideology in Eighteenth Century Britain. London: Weidenfeld and Nicolson.

Dunn, John. 1969. The Political Thought of John Locke. Cambridge: Cambridge University Press.

Dunn, John. 1984. John Locke. Oxford: Oxford University Press.

Goldwin, Robert A. 1963. John Locke. En History of Political Philosophy, edited by Strauss, L. y Cropsey, J. Chicago: Chicago University Press.

Grant, Ruth Weissboard. 1987. Locke's Education for Liberty. Chicago: Chicago University Press.

Haley, Kenneth Harold Dobson. 1968. The First Earl of Shaftesbury. Oxford: Clarendon Press.

Hobbes, Thomas. 2001 [1651]. Leviathan. (editado por Tuck, R.). Cambridge: Cambridge University Press.

Locke, John 2000, [1698]. Two Treatises of Government (editado por Laslett, P.). Cambridge: Cambridge University Press.

Locke, John. 2001 [1689]. Carta sobre la Tolerancia. Madrid: Ediciones Mestos.

Macpherson, Crawford Brough. 1964 [1962]. The Political Theory of Possessive Individualism, Hobbes to Locke. Oxford: Clarendon Press.

Marshall, John. 1994. John Locke: Resistance, Religion and Responsibility. Cambridge: Cambridge University Press.

Montes, Leonidas. 2004. Adam Smith in Context: A Critical Reassessment of some Central Components of His Thought. London: Palgrave Macmillan.

Tarcov, Nathan. 1984. John Locke's Liberalism. Chicago: Chicago University Press.

Tully, James. 1980. A Discourse on Property: John Locke and his Adversaries. Cambridge: Cambridge University Press.

Leonidas Montes L. es PhD, MPhil en Economía, King's College, Universidad de Cambridge. Ingeniero Civil, Licenciado en Filosofía y Magíster en Ciencia Política, Pontificia Universidad Católica de Chile. Actualmente es profesor de Economía, Universidad Adolfo Ibáñez, Santiago, Chile.

(E-mail: leonidas.montes@uai.cl) 